\title{
Construction and Application on English Autonomous Learning Resources
}

\author{
Mingjie Wang \\ College of Foreign Languages, Bohai University, Jinzhou, 121013, China \\ 1834078850@qq.com
}

\begin{abstract}
Keywords: English autonomous learning resources; construction; application; autonomous learning model
\end{abstract}

\begin{abstract}
Promote English teaching supported by modern information technology and network technology, to a certain extent, not limited by time and place, the direction of individualized and autonomous learning. This paper researches in order to adapt to the needs of English autonomous learning. First of all, the paper analyzes the research progress of autonomous learning model, Zimmerman's autonomous learning model structure is given; Then the autonomous learning resources construction process, especially on the analysis, design of learning resources and learning resources construction development tool selection and so on three key steps; Then, designed by listening, speaking, reading, writing, translation and vocabulary of English learning resources; Finally, the research on English autonomous learning resources organization, especially on four types such as short message, micro video, e-book and micro courseware.
\end{abstract}

\section{Introduction}

Autonomous learning is learning main body independent, productive, and discipline of study. Learning independence, self-behavior and self-discipline is the embodiment of the three aspects of learning autonomy, are the three basic characteristics of autonomous learning. Among them, the independence is the basis of autonomous learning, self-behavior is the essence of autonomous learning self-discipline is the guarantee of autonomous learning. This shows three characteristics are that the same thought: study subject is the master of his own learning, learning is ultimately dominated by learning subject yourself and complete. Acknowledge and sure this idea, the correct once had a lot of unreasonable education reform teaching means, mode, so as to explore to create a new education teaching means, mode, it has special important realistic meaning and function.

"College English curriculum requirements" points out that the institutions of higher learning should make full use of modern information technology, based on the computer and the classroom English teaching mode, the improvement is given priority to with teachers' teaching of the single teaching mode. New teaching model should be to modern information technology, especially network technology as the support, can make the teaching and learning of English in a certain extent, not limited by time and place, the direction of individualized and autonomous learning. New English teaching mode should reflect the principle of combining practical, informative and interesting teaching, is helpful to arouse the enthusiasm of teachers and students two aspects, especially want to reflect the subject status of students in the teaching process and teachers in a leading role in the process of teaching.

Construction of learning resources is the basis of using modern information technology and carry out autonomous learning, this paper studies English autonomous learning resources construction, and provide support for English autonomous learning, also provide a reference for other subjects of autonomous learning resources construction.

\section{Autonomous Learning Model}

Autonomous learning is up due to the rapid growth of knowledge and a constantly changing work environment. As an important teaching model of adult learning, the concept of autonomous learning and theory appeared in the $1970 \mathrm{~s}$, during the course of autonomous learning research, some 
scholars put forward the understanding of autonomous learning model. Representative include: M.aylor transition model of D.D.Pratt model of relationship between children's education and adult education R.G.Brockett personal responsibility orientation of autonomous learning model, G.O.Crow of autonomous learning model, L.D.Hammond critical autonomous learning model, B.Delahaye study four stage model, D.R.Garrison dimension of autonomous learning model, autonomous learning process model of Pilling-Cormick, R.E.Boyatzis autonomous learning theory model, etc. Zimmerman of autonomous learning model is the most representative, as shown in Fig. 1. The solid line shows the strategies used in this picture, dotted line feedback loop.

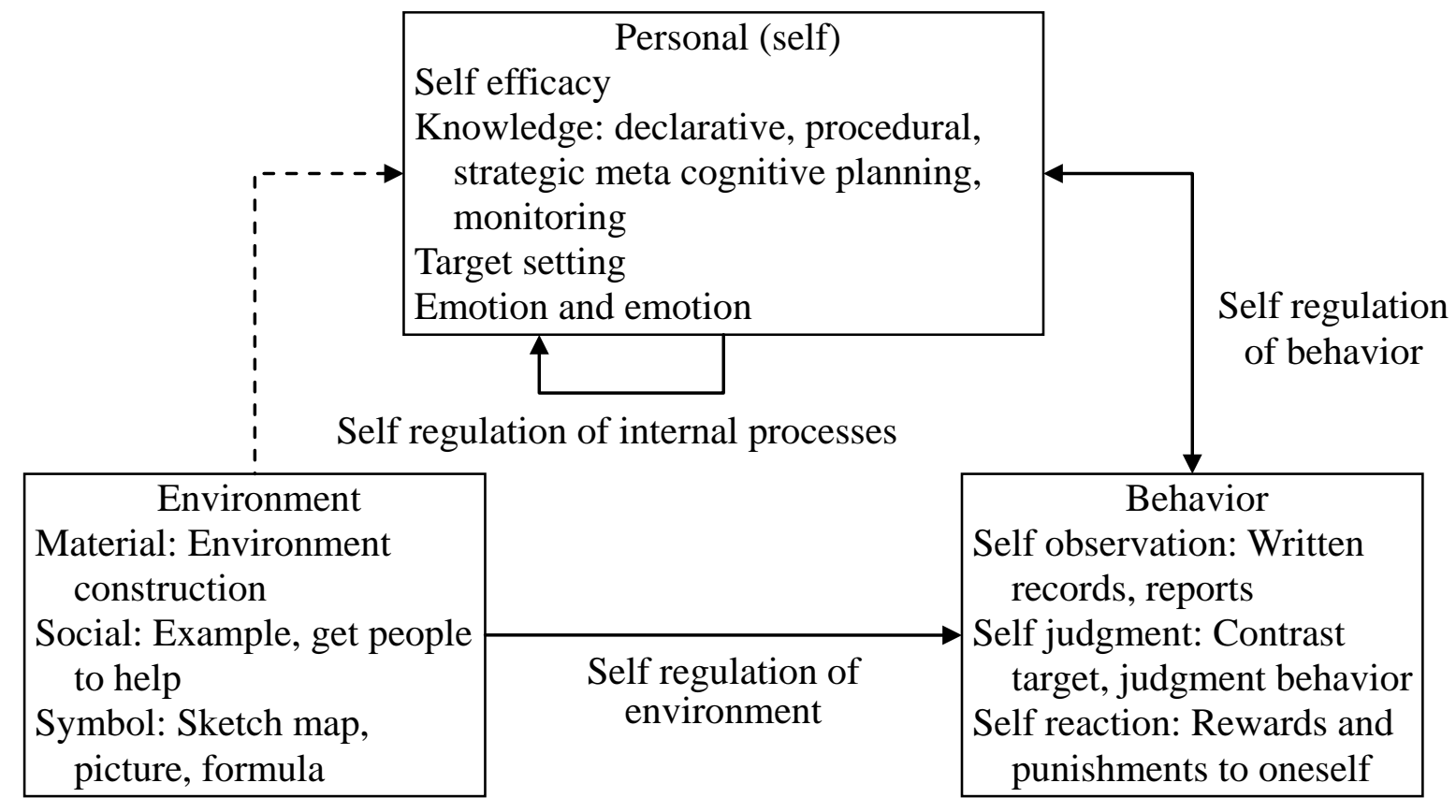

Fig. 1. Autonomous learning model of Zimmerman

\section{Construction Process on Autonomous Learning Resources}

Every stage of life cycle of the software development process based on the activities of the division, on the basis of user requirements can be converted to the software system the process of collection activities. The software development process includes requirements analysis, design, coding, integration, testing, installation and acceptance and other activities. Collect all aspects of the information (input) in the process of user demand, define the user product functionality and performance, by designing the user requirements into software, according to the logic function defined on the product, as coding framework and basis for the design results, finally through the programming design is transformed into machine-readable form. The entire software development process can be further divided into five components: feasibility study, requirements analysis, design, coding, testing. The division of the software development process, the software management and resource input and software project development success eventually is of great significance. To fully understand the definition of the various activities and tasks is in order to reasonably and accurately and objectively to arrange every phase of the work. Design of the software development process of autonomous learning resources construction process as shown in Fig. 2, from top to bottom, the arrow on the left said construction process; The right side of the arrow from the bottom up is said to modify and improve the process.

The construction process of shown in Fig. 2 of the three core steps are briefly described as follows:

(1) Learning resources construction analysis. First of all, technical analysis, fully consider all technical issues on resources construction, as far as possible using mature technology, introducing advanced technology carefully. Then is the analysis of function and performance analysis. Finally 
are other aspects of analysis, including learning goal, learners and the curriculum nature analysis, etc.

(2) Learning resource design. Content design should pay attention to knowledge unit short and concise, can continue to inspire and sustain learners' learning motivation and interest. Media design text design, graphic design, audio, video, animation, design elements, etc. Interaction design including learning content is relatively simple text messaging, and learning form of rich content browsing.

(3) Selection of development tools. This paper select SSH framework for development, a large enterprise Web application system development usually requires a good software architecture, facilitate collaborative development and extension to upgrade, now more popular open-source framework SSH (Spring, Struts, Hibernate), is a development of J2EE enterprise Web application of lightweight solution. With SSH framework, not only to achieve the complete separation of view, controller and model, but also realizes the separation of business logic layer and persistence layer. So no matter how changes in the front the model layer is little changes and database changes will not affect front-end and improves the reusability of the system.

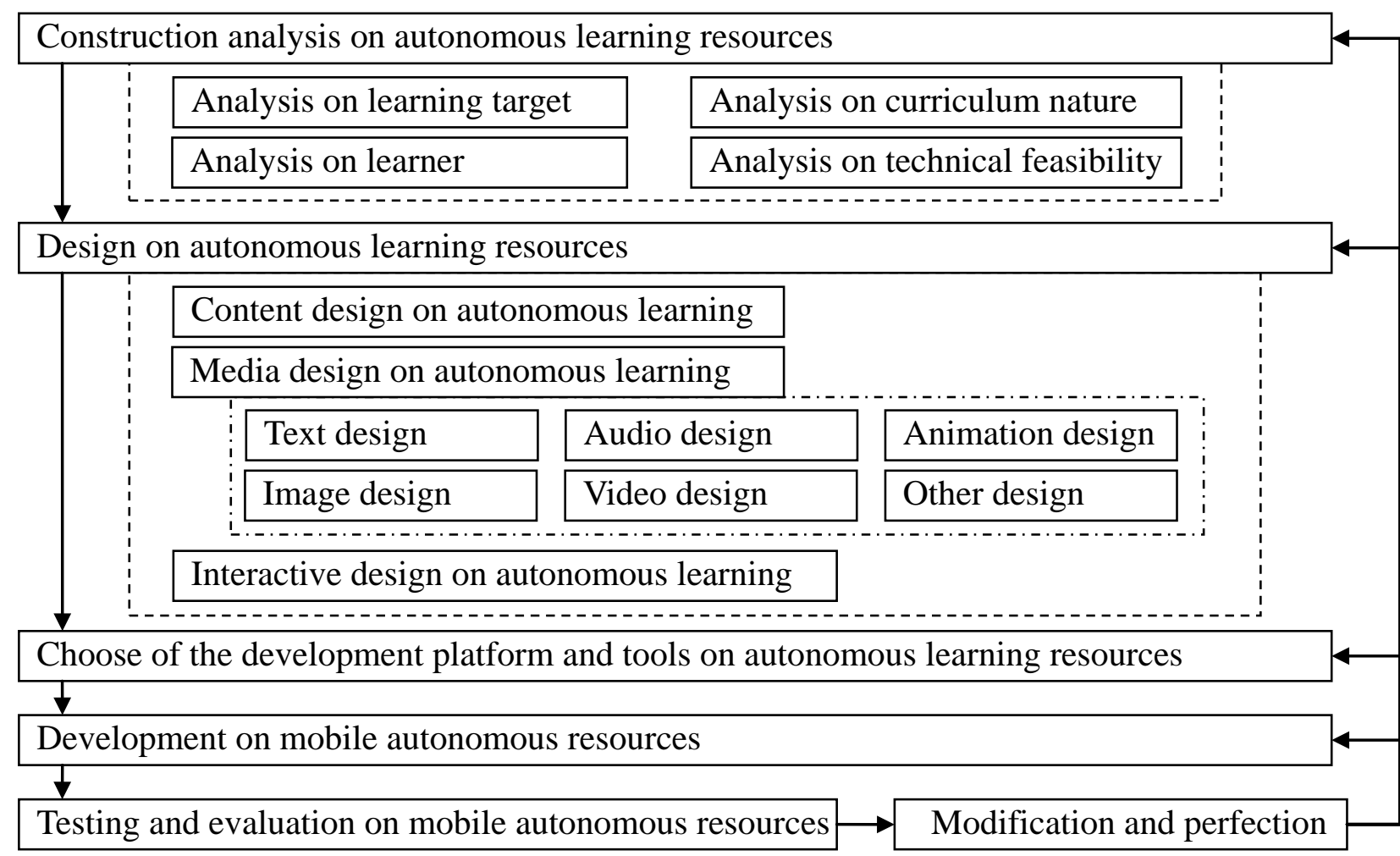

Fig. 2. Construction process on autonomous learning resources

\section{Composition on English Autonomous Learning Resources}

English autonomous learning resources is mainly provided by the teachers and be responsible for uploading and maintenance according to the "College English Curriculum Requirements" and "Outline of the university English four, six levels of tests", mainly provides listening, speaking, reading, writing, translation and vocabulary, etc. At the same time, to the student test study effect, provide resources for test and evaluation, etc. Resources are shown in Fig. 3.

\section{Organization on English Autonomous Learning Resources}

One of the characteristics of English teaching is as much as possible so that the students from different channels to contact and learn English in different ways, personal feeling and experience language and language use. English curriculum standard explicitly proposed that active development and rational utilization of curriculum resources is an important part of implementing 
English classroom. In English teaching, in addition to reasonable and effective use of textbooks, but should also actively other curriculum resources development and utilization. English education to cultivate the students' listening, speaking, reading, writing and translating "and other comprehensive ability, so autonomous learning resources also want to adapt to the requirement of training the ability. The text, images, audio, video, animation, and other types of material such as organizing, can form a short message, MMS, WeChat, web pages and courseware, micro video, e-book, electronic materials, animation, audio, video, E-mail, and microblog, and other forms of English autonomous learning resources. Structure as shown is in Fig. 4.

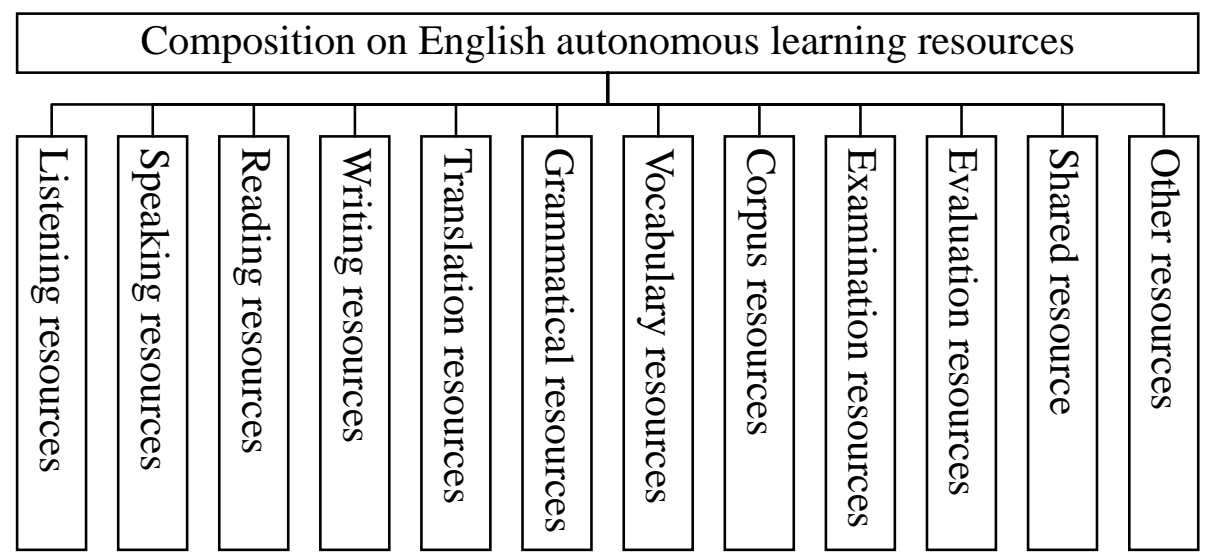

Fig. 3. Composition on English autonomous learning resources

In Fig. 4 involves more English learning resources type, the commonly used several brief introductions as follows:

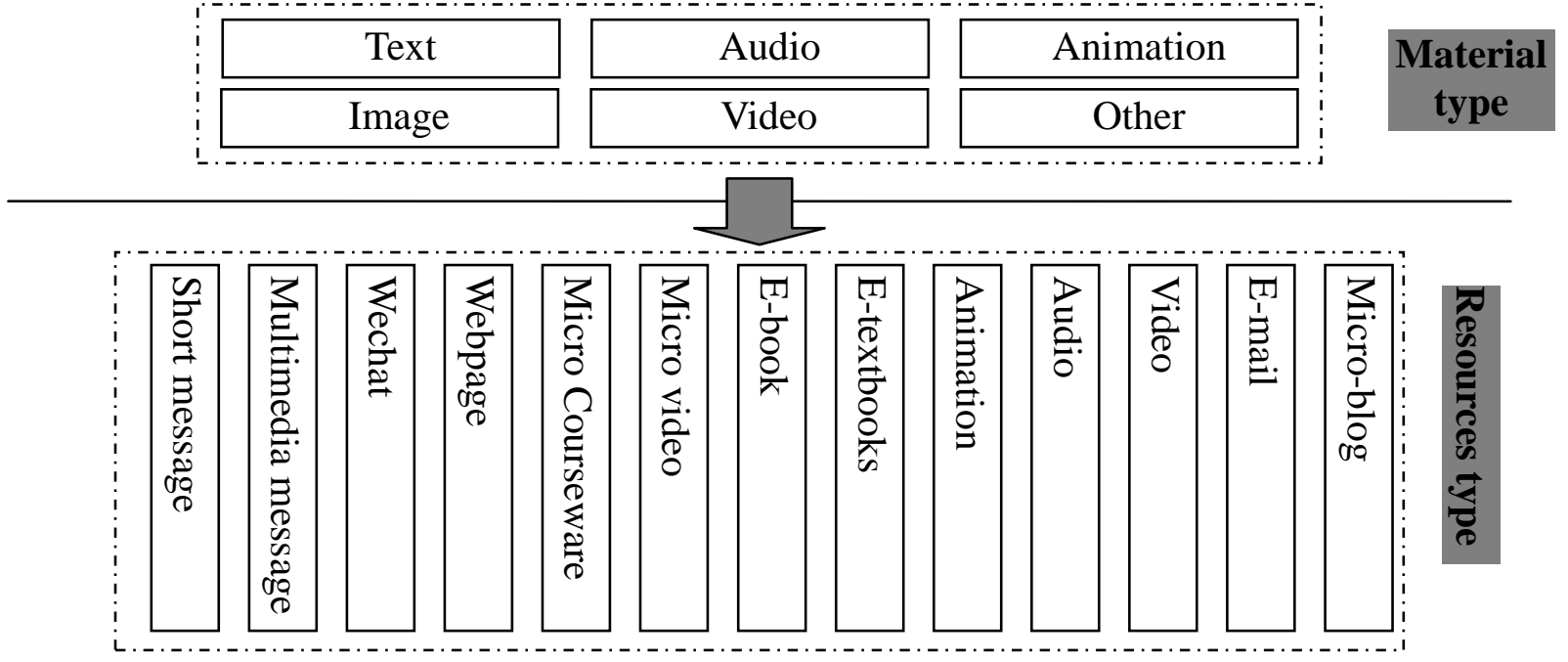

Fig. 4. Organization on English autonomous learning resources

(1) Short message. Short message through short message service center information transmission between the Internet and mobile phones, advantage is suitable for text information description, close to People's Daily habits, can real-time communication and low cost; The disadvantage is that a small amount of information, the length limit, present form lack of vitality. As college English autonomous learning resources, vocabulary or reading can be made into a short message, students can also send short message for themselves, teachers can mass short message.

(2) Video. Micro video teaching resources with the sharing of network resources, more and more used by people, people can through the network, to overcome the geographical and time limit sharing each grade school courses. Based on micro video learning resources can make learning content becomes vivid and intuitive, image, cause the attention of learners to the learned content, improve the enthusiasm of learning. Traditional classroom paper-based materials such as books, textbooks, learning content not only form a single and learners are prone to fatigue. In terms of English course, English is a language, learning English is used in real life, listening, speaking, 
reading, writing and so on each link all notes allow to ignore, micro video teaching resources, learners can not only watch the video, emphasis and difficulties, can also be repeated learning, to develop learners' ability of self.

(3) E-book. E-books from to paper as the carrier of traditional publications, can substitute the traditional paper books. By way of digital records in light, electricity, magnetic medium of equipment, with the aid of a specific device to read, copy, transfer. E-books easy to use, searchable content, change the font and font size, also can carry; Large capacity can be online at any time to download is not subject to regional restriction, save a lot of time. The entire content of the college English teaching material can be made into the form of e-books for students to use at any time, reading, translation, paper and other auxiliary resources are suitable for production into e-books.

(4) Courseware. Micro courseware is actual miniature courseware, is specially used in a variety of new media platforms play, suitable for use in mobile and short leisure state of learning software. Like ordinary courseware, the courseware can provide rich multimedia presentation and hypertext structure, also have to present the teaching content, teaching process control, evaluation of learning results and improve the learning interest, and other functions. But the courseware teaching content is not much, also had a shorter learning time. Listening, speaking, reading, translation and vocabulary can be made in the form of the courseware.

\section{References}

[1] X. Z. Li, X. H. Zhao, R. Ren, et al., "Research on the resources and environment construction of college English autonomous learning under the constructivism theory," Journal of Hubei University of Science and Technology, vol. 34, no. 9, pp. 121-122, 2014.

[2] W. H. Fan, "Research on the Construction and Application of Digital Resource in Higher Vocational English Autonomous Learning," Journal of Guangdong Communication Polytechnic, vol. 14, no. 4, pp. 86-89, 2015.

[3] Y. Zhang, S. P. Pan, "Theory of Zimmerman's Self-regulated Learning Model and Its Enlightenment," Higher Education Development and Evaluation, vol. 22, no. 1, pp. 48-50, 2006.

[4] T. L. Zhao, Y. Q. Tian, "A Review of Self-directed Learning Modelsin Western Countries: Implications for China," Modern University Education, vol. 29, no. 6, pp. 54-60, 2013.

[5] R. Zhou, Y. Gao, "The practice of formative assessment in college English autonomous learning," Journal of Ezhou University, vol. 23, no. 3, pp. 61-63, 2016.

[6] X. L. Li, C. J. Tang, X. Q. Wang, "On the construction of teaching resource database in College English Autonomous Learning Mode under Network Environment," Time Education, vol. 12, no. 19, pp. 246-246, 2015. 